\title{
A Cytological Study of Magnolia championii Benth. (Magnoliaceae)
}

\author{
Yaling Wang ${ }^{1,2}$, Zican $\mathrm{He}^{2}$ and Shouzhou Zhang ${ }^{2, *}$ \\ ${ }^{1}$ Xi'an Botanical Garden, Xi'an 710061, China. \\ ${ }^{2}$ Shenzhen Fairylake Botanical Garden, Shenzhen 518004, China.
}

Received January 16, 2008; accepted February 11, 2008

\begin{abstract}
Summary An analysis of the karyotype and meiotic behavior of Magnolia championii Benth. is presented. Its chromosome number is confirmed to be $2 n=2 x=38$. The ratio of the longest chromosome to the shortest chromosome is 2.31 and the karyotype is categorized to be $2 \mathrm{~B}$ type. The index of karyotype asymmetry is about $56.47 \%$, which is similar to other Magnolias. The meiosis process is normal except for one or two univalent pairs caused by the advanced disjunction of few bivalents. Single chromatid bridges and double chromatid bridges are observed at meiotic metaphase I in pollen mother cells and microspore tetrads. The low ratio of the abnormality, as shown in the research, does not constitute the main cause of the aborted pollen grains.
\end{abstract}

Key words Karyotype, Magnolia championii, Meiosis.

Magnolia championii Benth., a Magnoliaceae Jussieu. genus Magnolia Linn. subgenus Magnolia Dandy section Gwillimia DC., grows in Guizhou, south Guangxi and south-east and southwest of Canton. Its population, as the population reproduction model shows, has been on the decline, either in terms of the total number or in terms of its locations. The plants are difficult to find in the areas where specimens were collected in the past. That explains the fact that M. championii has been listed in the Forestry Regulations of Hong Kong.

Chromosomes often provide the students of evolution and phylogeny with valuable signposts which reveal the nature of the evolutionary processes at work and the trends which evolution has taken (Stebbins 1971). The abnormal behavior in meiotic processes indicates the endangered mechanism of vulnerable plants.

With an investigation into the number of the chromosome, karyotype of $M$. championii, and the meiotic processes of its pollen mother cells, this dissertation aims at accumulating more cytological data for phylogenetic research of Magnoliaceae and assigning the cytological reason for the low activity pollens.

\section{Materials and methods}

The sample plant under investigation grows in Shenzhen Fairylake Garden, where voucher specimens (Wang YL009) of the studied material are deposited. Somatic chromosome number and karyotype analysis were carried out on meristematic cells of root tips obtained from seedlings. Roots were pretreated in 8-hydroxyquinoline $(0.002 \% \mathrm{w} / \mathrm{v})$ for $2 \mathrm{~h}$, then fixed and stored in Carnoy I ( $3: 1$ ethanol-acetic acid) for $2 \mathrm{~h}$. Eligible floral buds for meiotic studies, obtained merely from the tree growing at the garden, were fixed in Carnoy I for 8-24 h.

Flame-drying protocol after enzyme digestion of cell wall was applied in getting chromosome slides (Zhu 1982) and chromosomes were stained in Giemsa. Metaphase plates were observed and photographed under the microscope (Zeiss Axioplan 2 Imaging Microscope). More than 20

*Corresponding author, e-mail: shouzhouz@yahoo.com.cn 

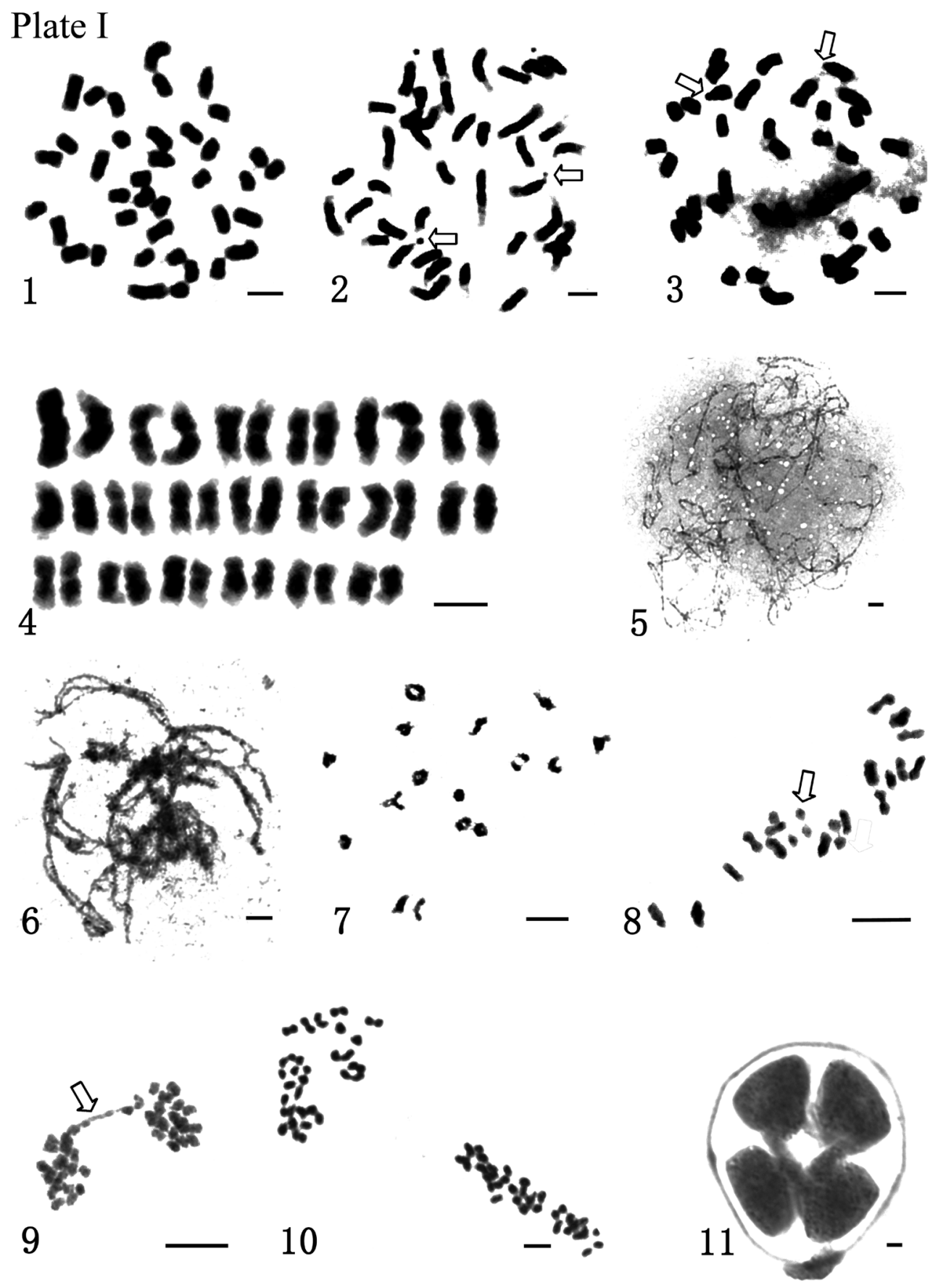

Plate I. 1-4. The mitosis and karyotype of Magnolia championii Benth. Bar $=2 \mu \mathrm{m}: 1$. Metaphase $(2 n=2 x=38) ; 2$. Metaphase, arrow showing satellites; 3. Metaphase, arrow showing st chromosomes; 4 . Karyotype of M. championii; 5-11. The Meiotic chromosome configuration of PMCs of Magnolia championii Benth. Bar $=5 \mu \mathrm{m}$ : 5. Leptotene; 6. Zygotene; 7. Diakinesis; 8 . Metaphase I, arrows indicate the univalent pair; 9. Anaphase I, showing single chromatid bridge; 10. Metaphase II, showing nonsynchromization; 11. Microspore tetrads, showing double chromatid bridge. 
Table 1. The karyomorphological parameters of M. championii

\begin{tabular}{rccc|cccc}
\hline \hline Pair No. & $\begin{array}{c}\text { Relative } \\
\text { length \% }\end{array}$ & Arm ratio & Type & Pair No. & $\begin{array}{c}\text { Relative } \\
\text { length \% }\end{array}$ & Arm ratio & Type \\
\hline 1 & 7.10 & 1.08 & $\mathrm{~m}$ & 11 & 5.04 & 1.03 & $\mathrm{~m}$ \\
2 & 6.68 & 1.06 & $\mathrm{~m}$ & 12 & 5.03 & 1.74 & $\mathrm{sm}$ \\
3 & 6.50 & 1.29 & $\mathrm{~m}$ & 13 & 4.98 & 1.45 & $\mathrm{~m}$ \\
4 & 5.83 & 1.11 & $\mathrm{~m}$ & 14 & 4.92 & 1.21 & $\mathrm{~m}$ \\
5 & 5.77 & 1.22 & $\mathrm{~m}$ & 15 & 4.51 & 1.16 & $\mathrm{~m}$ \\
6 & 5.73 & 1.05 & $\mathrm{~m}$ & 16 & 4.28 & 2.67 & $\mathrm{sm}$ \\
7 & 5.69 & 1.14 & $\mathrm{~m}$ & 17 & 4.20 & 3.16 & $\mathrm{st}$ \\
8 & 5.55 & 1.16 & $\mathrm{~m}$ & 18 & 4.06 & 1.59 & $\mathrm{~m}$ \\
9 & 5.35 & 1.15 & $\mathrm{~m}$ & 19 & 3.44 & 1.34 & $\mathrm{~m}$ \\
10 & 5.33 & 1.29 & $\mathrm{~m}$ & & & & \\
\hline
\end{tabular}

Table 2. A comparison of karyotype characteristics between some species in section Gwillimia DC.

\begin{tabular}{llcccc}
\hline \hline \multicolumn{1}{c}{ Species } & \multicolumn{1}{c}{ Karyotype formula } & $\begin{array}{c}\text { Asymmetry } \\
\text { index }\end{array}$ & $\begin{array}{c}\text { Ratio of } \\
\text { chromosome } \\
\text { length (L/S) }\end{array}$ & $\begin{array}{c}\text { Karyotype } \\
\text { type }\end{array}$ & Author \\
\hline M. championii & $32 \mathrm{~m}(2 \mathrm{SAT})+4 \mathrm{sm}+2 \mathrm{st}$ & 56.47 & 2.3 & $2 \mathrm{~B}$ & Present author \\
M. delavayii & $30 \mathrm{~m}+6 \mathrm{sm}+2 \mathrm{st}(2 \mathrm{SAT})$ & 57.02 & 2.6 & $2 \mathrm{~B}$ & Li et al. (1998) \\
M. delavayi & $32 \mathrm{~m}+4 \mathrm{sm}(2 \mathrm{SAT})+2 \mathrm{st}(2 \mathrm{SAT})$ & 56.99 & 2.0 & $2 \mathrm{~B}$ & Li et al. $(1998)$ \\
M. coco & $32 \mathrm{~m}+4 \mathrm{sm}+2 \mathrm{st}(2 \mathrm{SAT})$ & 56.28 & 2.2 & $2 \mathrm{~B}$ & Li et al. $(1998)$ \\
\hline
\end{tabular}

metaphase cells were observed to determine the chromosome number and three metaphase cells were measured for karyotypical analysis. The chromosome classification followed Levan et al. (1964) and Stebbins (1971) standard, and the karyotype asymmetry index followed Arano (1963). The results are as follows (Plate I).

\section{Results}

\section{Karyotypical analysis}

All the somatic cells observed have $2 n=2 x=38$ chromosomes (Plate I: 1 ). The karyotype is $2 n=2 x=38=32 \mathrm{~m}(2 \mathrm{SAT})+4 \mathrm{sm}+2 \mathrm{st}$, and belongs to $2 \mathrm{~B}$ (Plate I: $2,3,4)$. One pair of $\mathrm{m}$ chromosomes have satellite, which are sometimes indistinct and invisible (Plate I: 2). The mean chromosome length ranges between $1.63-3.76 \mu \mathrm{m}$, with a total chromosome length of $100.84 \mu \mathrm{m}$. The longest chromosome is $3.58 \mu \mathrm{m}$, and the shortest $1.73 \mu \mathrm{m}$. The ratio of the longest to the shortest is 2.31. The index of karyotype asymmetry is about $56.47 \%$. Karyomorphological parameters are given in Table 1.

\section{Meiotic observations}

In the meiotic prophase of pollen mother cell (PMC), the chromosomes are thin, long and entangled with each other, and therefore could not be distinguished easily (Plate I: 5, 6). In metaphase I, 19 bivalents are formed, eight of which are the ring type, and eleven the rod type (Plate I: 7).

A few bivalents divided ahead of their due time into chromatids (Plate I: 8). During the division, the bivalents grouped in two move separately to the two poles of the cell in anaphase I. Single chromatid bridges are observed at anaphase I (Plate I: 9). A regular pattern of division is perceived in anaphase II except for slight non-synchronization division of two cells (Plate I: 10). The double chromatid bridges are observed in microspore tetrads (Plate I: 11). Of the 25 PMCs observed, only one cell carries the chromatid bridge. So the ratio of the abnormality is as low as $4 \%$. 


\section{Discussion}

\section{Karyotype characterization of section Gwillimia DC}

Section Gwillimia DC., composed of about 20 species, is a primitive group in Magnoliaceae. Results of the eight studied species so far show that their chromosome numbers are all $2 n=38$. Because of the small size, their karyotype analysis has only been tried on a few species. The index of karyotype asymmetry varies between 53.7 and 59. Most of them are m-chromosome or sm-chromosome with one or three satellites. Resembling each other morphologically, the karyotype of $M$. championii is also similar to M. coco (Lour.) DC., except for the position of the satellites, which are generally very easy to be lost.

The karyotypes of most species in Magnoliaceae are of the symmetry type and have little diversification. Most of them are 2B type, except for the genus Liriodendron L. and Michelia L., which are the 2A type (Chen et al. 2000). According to the karyotype classification of Stebbins (1971), A type is more primitive than B. In the whole family, the genera Liriodendron and Michelia, have quite an advanced position. By contrast, the karyotype of Manglietia and Magnolia section Gwillimia, the primitive groups, are B type, the advanced one.

\section{The meiotic behavior of Magnoliaceae}

Up to now, only a little meiotic behavior information about the family Magnoliaceae (He et al. 2005, Li and He 2003, Wang et al. 2004) is available, as different varieties like diploid, tetraploid, hexaploid in Magnoliaceae differ from each other in their meiotic behaviors. Regular behavior is shared by most diploid, such as $M$. championii, M. coco, M. paenetalauma Dandy, M. delavayi Franch. and M. figo (Lour.) Spreng. (Wang et al. 2004), with the exception of some lagging chromosomes which result in quinquefid spores (unpublished information). At meiotic anaphase I, single chromatid bridge of $M$. championii's PMCs is formed due to once sister-chromatid exchange, and this in turn determines a fertility rate of $50 \%$ of the pollens. Meanwhile the formation of the double chromatid bridge is caused by twice chromatid exchange, which is responsible for the sterile pollens (Zhang et al. 1997). Since the ratio of the abnormality is only $4 \%$ and produces $2 \%$ abnormal pollens only, it follows that the abnormal meiotic does not constitute a main cause for the aborted pollen grains compared with a rate of $0-30 \%$ of pollen germination.

\section{References}

Arano, H. 1963. Cytological studied in subfamily Carduoideae (Compositae) of Japan IX. Botanic Magazine (Tokyo) 76: $32-39$.

Chen, Z. Y., Huang X. X., Wang, R. J. and Chen S. J. 2000. Chromosome Data of Magnoliaceae. In: Law et al. Proceedings of the International symposium on the Family Magnoliaceae. Science Press, Beijing. pp. 192-201.

He, Z. C., Li, X. D. and Li, J. Q. 2005. Meiotic observations on the pollen mother cells of Manglietia patungensis, an endangered species. Acta Phytotaxonomica Sinica 43: 526-532.

Levan, A., Fredge, K. and Sandberg, A. A. 1964. Nomenclature for centromeric position on chromosomes. Hereditas 52: 201-220.

Li, J. Q. and He, Z. C. 2003. Meiosis observation and chromosome configuration analysis of Magnolia denudata. Acta Phytotaxonomica Sinica 41: 362-368.

Li, X. L., Song, W. Q., An, Z. P. and Chen, R. Y. 1998. Karyotype analysis of some species of Magnolia in China. Acta Botanica Yunnanica 20: 204-206.

Stebbins, G. L. 1971. Chromosomal evolution in higher plants. Edward Arnold Ltd., London.

Wang, Q., Wang, H. C. and Xu, L. M. 2004. A cytological study on the cytology of Michelia figo (Magnoliaceae). Journal of Wuhan Botanical Research 22: 87-89.

Zhang, S. Z., Pan, K. Y., Zhang, D. M. and Hong, D. Y. 1997. Observations on abnormal meiosis of pollen mother cells in Paeonia Suffruticosa subsp. Spontanea. Acta Botanica Sinica 39: 397-404.

Zhu, C. 1982. Plant Chromosome and Chromosomal Technique. Science Press, Beijing. 